\title{
Effects of aqueous Anaphe venata extract on fecal pellet output in mice
}

\author{
Rufus O. AKOMOLAFE ${ }^{1 *}$, Kayode D.S. BAMITALE ${ }^{1}$, Ezekiel O. IWALEWA ${ }^{2}$, \\ Olasupo S. ADENIYI ${ }^{3}$, Abiodun O. AYOKA ${ }^{1}$ and Isaac O. ADEOSHUN ${ }^{1}$ \\ ${ }^{I}$ Department of Physiological Sciences, Faculty of Basic Medical Sciences, College of Health Sciences, \\ Obafemi Awolowo University, Ile Ife, Nigeria. \\ ${ }^{2}$ Department of Pharmacology, Faculty of Pharmacy, Obafemi Awolowo University, Ile Ife, Nigeria. \\ ${ }^{3}$ Department of Physiology, Faculty of Basic and Allied Medical Sciences, College of Health Sciences, \\ Benue State University, Makurdi, Nigeria. \\ *Corresponding author, E-mail: rufakom@yahoo.co.uk; Tel: 2348034393396
}

\begin{abstract}
The consumption of Silkworm, Anaphe venata has been reported to be associated with a high incidence of seasonal ataxia in some parts of Nigeria. Injection of some doses of Aqueous Anaphe venata extract (AAV) by intraperitoneal route into mice has been reported to cause some behavioral changes associated with ataxia. We administered some doses of the extract $(50-300 \mathrm{mg} / \mathrm{kg})$ to mice orally in view of finding its effects on their fecal pellet output and elucidating the mechanism of action of the extract in the intestine of the mice. The extract caused a significant increase in fecal pellet weight and intestinal transit which was not dose-dependent. Doses of 200 and $300 \mathrm{mg} / \mathrm{kg}$ of the extract caused more significant reversal of loperamide-induced constipation than castor oil. Chlorpheniramine nifedipine and promethazine $(1 \mathrm{mg} / \mathrm{kg})$ blocked the increased fecal pellet output induced by the extract, while atropine and hexamethonium $(1 \mathrm{mg} / \mathrm{kg})$ did not block this effect of the extract. We concluded that AAV increased fecal pellet output of mice by increasing the peristaltic waves in their intestine via stimulation of $\mathrm{H}_{1}$ receptors and opening of L-type calcium channels and not through the cholinergic receptors.
\end{abstract}

(c) 2011 International Formulae Group. All rights reserved.

Keywords: $\mathrm{H}_{1}$ receptors, L-type calcium channels, intestinal transit, peristalsis.

\section{INTRODUCTION}

Worms and insects are very common delicacies in developing countries of the world, due to their accessibility, affordability and high protein content (Ene, 1963; De Follart, 1989, 1992).

Anaphe Venata larvae (African Silkworm) is one of the worms that are eaten by people in the Western and Middle Belt regions of Nigeria as components of soup or refreshment items in restaurants, because they are very rich in protein (Umoh et al., 1980; Ashiru, 1988). The worms have also been shown to contain amino acids, fats and sterols (Onayade et al., 2004). Seasonal ataxia associated with consumption of these larvae has been reported (Adamolekun, 1992). Studies in mice confirmed that both polar and 
non-polar extracts of these worms, induced increase in behavioural components as tremor, jerking and stretching after intraperitoneal administration of the extractions for 7 days, an indication of Ataxia syndrome (Iwalewa et al., 2005)

However, there is a dearth of information on the effects of these worms on the intestine, the route through which they are taken into the body. The study was carried out to find the effect of the aqueous extract of Anaphe venata (AAV) on defecation in mice and to elucidate the mechanisms of action of the extract.

\section{MATERIALS AND METHODS Preparation of $A$. venata extract}

Dried Anaphe venata larvae were purchased from a market in Ile Ife, Osun State, Nigeria and authentication was done by Professor W. A. Muse in the Department of Zoology, Obafemi Awolowo University, Ile Ife.

The powdered larvae (150 g) were extracted cold in 2 liters of distilled water with continuous shaking for 24 hours in a mechanical shaker. The mixture was filtered and then freeze dried to obtain the aqueous extract. The total aqueous extract obtained was $6.5 \mathrm{~g} \quad(4.3 \%$ yield w/w $)$. Chemical analysis of the extract was carried out in the Chemistry Department of Benue State University, Makurdi, Nigeria using standard methods.

\section{Experimental animals}

Swiss mice of both sexes (25-30 g) were used for the experiments. Prior to the experiments, the animals were housed under standard controlled environmental conditions with a 12 hour light/dark cycle and with food (Pfizer Feed Plc, Nigeria) and water provided ad libitum. The mice were kept in plastic cages whose floors were lined with white blotting paper. Wire gauze was placed about 2 $\mathrm{cm}$ above the papers so as to prevent the mice from eating up the papers. The mice were placed on the wire gauze for two weeks before the experiment in order to allow them to be familiar with the environment. The care and use of the animals and the experimental protocol of this study were in accordance with Experimental Animal Care and Use Regulation of the Animal House, College of Health Sciences, Benue State University, Makurdi, Nigeria which were also in accordance with the internationally accepted principles for laboratory animal use (EEC Directive of 1986; 86/609/EEC). For all the experiments, the animals were fasted for 16 hours before treatment.

\section{Drugs and treatments}

Nifedipine (NIF) was purchased from Medrel Pharmaceutical (India) PVT Ltd. Chlopheniramine (CHL), Atropine sulphate (ATR), Promethazine (PRO), Hexamethonium (HEX), Activated Charcoal, Sodium Chloride, Castor oil (CO) were obtained from Sigma Chemical Company, USA. All drugs and extract were dissolved in normal saline $(0.9 \%$ sodium chloride solution) before being administered to mice.

\section{Effects on fecal pellet output}

Thirty mice were used for this aspect of the study. They were divided into six groups of five mice each. Each mouse was put in a separate cage. Each of Group 1 mice which served as the positive control was given 0.25 $\mathrm{ml}$ (p.o.) of normal saline (NS). Group 2, the negative control, got $3 \mathrm{mg} / \mathrm{kg} \mathrm{CO}$ each. Each mouse in groups 3-6 received $0.25 \mathrm{ml}$ of AAV equivalent to $50,100,200$ and $300 \mathrm{mg} / \mathrm{kg}$ of the extract respectively, a modification of the method of Ojewole et al. (2008). The fecal pellets of each mouse were counted every 2 hours from the time of treatment for the first 8 hrs and then overnight ( 24 hours), so as to assess their recovery. The presence of wet feces was also noted for each group. The pellets were air dried for another 24 hours 
before weighing. The average of the number and weight of the pellets was taken as the output for each mouse in the group.

\section{Effects on loperamide induced constipation}

The two doses of AAV that produced the greatest fecal pellet weights (200 and 300 $\mathrm{mg} / \mathrm{kg}$ ) were used as the Working Dose for this study. Twenty mice of both sexes were divided into four groups of five mice each. Group 1 received $0.25 \mathrm{ml}$ NS by oral administration. Groups $2-4$ received $10 \mathrm{mg} / \mathrm{kg}$ of loperamide each (p.o.). Thirty minutes later, group 2 received $3 \mathrm{ml} / \mathrm{kg}$ castor oil each, while each mouse in groups 3 and 4 got 200 and $300 \mathrm{mg} / \mathrm{kg}$ AAV respectively. The fecal pellet output of each group was also recorded as stated in the first experiment above.

\section{Effects of some receptor blockers on AAV- induced defecation}

The dose of AAV that consistently produced the highest number and weight of fecal pellets and provided the greatest protection against loperamide-induced constipation $(200 \mathrm{mg} / \mathrm{kg})$ was selected as the Working Dose for this experiment. Thirty mice were used for this study. They were divided into six groups of 5 mice each. Group 1 was pre-treated with $0.25 \mathrm{ml} \mathrm{NS}$ (i.p.), while groups 2-6 were given $1 \mathrm{mg} / \mathrm{kg}$ of the receptor blockers written against their names by intraperitoneal route as follows: group 2 (ATR), group 3 (CHL), group 4 (PRO), group 5 (NIF) and group 6 (HEX). Twenty minutes later, each animal was administered 200 $\mathrm{mg} / \mathrm{kg}$ AAV (p.o.) and the fecal pellet output was recorded as in the first experiment.

\section{Effects on intestinal transit}

The method of Gamaliel et al., (1996) was used. Thirty mice were divided into six groups of 5 mice each. Group 1 was given $0.25 \mathrm{ml}$ (p.o) of NS each. Group 2 received $3 \mathrm{ml} / \mathrm{kg}$ CO (p.o.) each. Groups 3-6 received $0.25 \mathrm{ml}$ of AAV equivalent to $50,100,200$ and
$300 \mathrm{mg} / \mathrm{kg}$ respectively. After 30 minutes, the animals were given $0.1 \mathrm{ml}$ of freshly prepared charcoal meal (10\% in NS) orally. Thirty minutes after charcoal meal administration, the mice were anaesthetized with chloroform. They were sacrificed by cervical dislocation and the abdomen immediately cut open to dissect out the whole small intestine (pylorus region to caecum). The length of the small intestine and the distance between the pylorus region and the front of the charcoal meal was measured for obtaining the charcoal transport ratio or percentage, that is the percentage of the entire small intestine travelled by the charcoal meal after 30 minutes.

\section{Statistical analysis}

Each value was expressed as mean \pm SD. Significant changes in number and weight of fecal pellets and the distance travelled by charcoal meal along the small intestine following various treatments were analyzed using one-way analysis of variance (ANOVA) followed by Tukey-Kramer Multiple Comparisons Test. P-value equal to or less than 0.05 was taken as significant. Data management was carried out using GraphPad InStat Biostatistics Programme, Version 3.06, USA (2010).

\section{RESULTS}

\section{Effects of AAV on the number of fecal pellets}

The effect of the doses of AAV used in this study (50-300 mg/kg) on the number of fecal pellets produced by the mice was not dose-dependent (Table 1).Only $200 \mathrm{mg} / \mathrm{kg}$ of AAV produced a significantly higher number of fecal pellets than NS throughout the study. It also caused significantly higher number fecal pellets than CO except at the fourth hour of study. All other doses of the extract produced inconsistent changes in the number of fecal pellets of the mice. The number of fecal pellets produced by $\mathrm{CO}$ got to its peak at the fourth hour of the study, while all the 
doses of AAV used caused gradual increases in fecal pellet output throughout the study.

Effects of AAV on the weight of fecal pellets

All the doses of AAV produced significantly higher fecal pellet weights than NS throughout the study (Table 2). With CO, the pellet weight got to its peak at the 4th hour of the study, while all the doses of AAV produced gradual increases in fecal pellet weight. A dose of $200 \mathrm{mg} / \mathrm{kg}$ of $\mathrm{AAV}$ produced significantly higher pellet weight than $\mathrm{CO}$ between $6^{\text {th }}$ and $24^{\text {th }}$ hour of the study. It was only at the $24^{\text {th }}$ hour of the study that 100 and $300 \mathrm{mg} / \mathrm{kg}$ of AAV produced a significantly higher pellet weight than $\mathrm{CO}$.

\section{Effects of AAV on intestinal transit}

Doses of AAV caused more significant but not dose-dependent increases in intestinal transit than NS and CO up till $200 \mathrm{mg} / \mathrm{kg}$ (Table 3). At $300 \mathrm{mg} / \mathrm{kg}$, intestinal transit was significantly lower than both in NS and CO.

\section{Effects of AAV on the number of fecal pellets following loperamide-induced constipation}

Following loperamide-induced

constipation, $\mathrm{CO}$ produced significantly lower number of fecal pellets than NS in most part of the study, while $200 \mathrm{mg} / \mathrm{kg}$ of AAV produced significantly higher number of fecal pellets than $\mathrm{CO}$ (Table 4). The results indicate that AAV was able to reverse the loperamideinduced constipation better than $\mathrm{CO}$.

Effects of AAV on the weight of fecal pellets following loperamide-induced constipation

Castor oil (CO) produced significantly lower fecal pellet weights than NS throughout the study, while 200 and $300 \mathrm{mg} / \mathrm{kg}$ of AAV produced significantly higher weights of fecal pellets than $\mathrm{CO}$ and significantly lower fecal pellet weights than NS in most parts of the study (Table 5). $200 \mathrm{mg} / \mathrm{kg}$ of AAV produced significantly higher fecal pellet weights than $300 \mathrm{mg} / \mathrm{kg}$ in the first eight hours of the study. This indicates that the doses of AAV used in the study caused a more significant reversal of loperamide-induced constipation than $\mathrm{CO}$ in mice. The greater reversal was caused by 200 $\mathrm{mg} / \mathrm{kg}$ of the extract.

Effects of some receptor blockers on the number of fecal pellets following administration of AAV

Compared to NS, ATR produced a significantly lower number of fecal pellets only in the $2^{\text {nd }}$ hour of the study (Table 6); CHL and PRO did the same up to the $6^{\text {th }}$ and $8^{\text {th }}$ hours of the study respectively, while NIF did likewise throughout the study. HEX caused a more significant increase in fecal pellet number only in the $24^{\text {th }}$ hour of the study. This indicates that the most effective blocker of the increased spontaneous defecation caused by AAV is NIF.

Effects of some receptor blockers on the
weight of fecal pellets following
administration of AAV
Compared to NS, ATR caused a significantly higher fecal pellet weight throughout the study, except in the $2^{\text {nd }}$ hour when it was significantly lower (Table 7); CHL, PRO and NIF produced significantly lower fecal pellet weights throughout the study, while HEX produced significantly higher weights of fecal pellets throughout the experiment. NIF produced the most significant reduction in pellet weights, indicating that it is the most effective blocker of the increased fecal pellet output caused by AAV. 
Table 1: Effects of AAV on pellet number.

\begin{tabular}{|c|c|c|c|c|c|}
\hline \multirow[t]{2}{*}{ Dose } & 2nd hr & 4th hr & 6th hr & 8th hr & 24th hr \\
\hline & No & No & No & No & No \\
\hline Nor mal. S. & $2.80 \pm 0.84$ & $5.00 \pm 0.71$ & $5.80 \pm 0.45$ & $7.00 \pm 0.71$ & $7.80 \pm 0.45$ \\
\hline Castor Oil & $3.40 \pm 0.55$ & $7.00 \pm 0.71^{\text {aaa }}$ & $7.00 \pm 0.71^{\mathrm{a}}$ & $7.00 \pm 0.71$ & $7.00 \pm 0.71$ \\
\hline $50 \mathrm{mg} / \mathrm{kg}$ & $3.80 \pm 0.45$ & $5.80 \pm 0.45^{\mathrm{b}}$ & $7.00 \pm 0.71^{\mathrm{a}}$ & $7.40 \pm 0.55$ & $8.40 \pm 0.55$ \\
\hline $100 \mathrm{mg} / \mathrm{kg}$ & $2.80 \pm 0.84$ & $4.40 \pm 0.55^{\mathrm{bbbcc}}$ & $5.40 \pm 0.55^{\mathrm{bbcc}}$ & $5.80 \pm 0.45^{\mathrm{cc}}$ & $9.80 \pm 1.30^{\mathrm{a} b b b}$ \\
\hline $200 \mathrm{mg} / \mathrm{kg}$ & $5.20 \pm 0.45^{\text {aaa bbb cc ddd }}$ & $6.20 \pm 0.45^{\text {a ddd }}$ & $9.40 \pm 0.55^{\text {aaa bbb ccc ddd }}$ & $11.00 \pm 0.71^{\text {aaa bbb ccc ddd }}$ & $12.60 \pm 0.55^{\text {aaa bbb ccc ddd }}$ \\
\hline $300 \mathrm{mg} / \mathrm{kg}$ & $4.40 \pm 0.55^{\text {aa dd }}$ & $6.20 \pm 0.4^{\mathrm{a} \mathrm{ddd}}$ & $6.20 \pm 0.45$ & $6.60 \pm 0.55$ & $10.40 \pm 1.14^{\text {aaa bbb c }}$ \\
\hline
\end{tabular}


Table 2: Effects of AAV on pellet weight.

\begin{tabular}{|c|c|c|c|c|c|}
\hline Dose & 2nd hr & 4th hr & 6th hr & 8th hr & 24th hr \\
\hline & Wt (mg) & Wt (mg) & Wt (mg) & Wt (mg) & Wt (mg) \\
\hline Nor mal. Saline (NS) & $28.00 \pm 0.16$ & $51.40 \pm 0.24$ & $58.40 \pm 0.20$ & $72.20 \pm 0.21$ & $84.72 \pm 0.10$ \\
\hline Castor Oil (CO) & $54.40 \pm 0.20$ aаa & $107.00 \pm 0.26^{\text {aaa }}$ & $107.00 \pm 0.26^{\text {aaa }}$ & $107.00 \pm 0.26^{\text {aa }}$ & $107.00 \pm 0.11^{\text {aaa }}$ \\
\hline $50 \mathrm{mg} / \mathrm{kg}$ & $44.56+0.22$ aaa bbb & $63.80+\overline{0} .12^{\text {aaa bbb }}$ & $76.00+\overline{0} .12^{\text {aaa bbb }}$ & $79.60+\overline{0} .21^{\text {aaa bbb }}$ & $87.40+\overline{0} .07^{\text {aaa bbb }}$ \\
\hline $100 \mathrm{mg} / \mathrm{kg}$ & $49.00 \pm 0.35^{\text {aaa bbb ccc }}$ & $63.20 \pm 0.20^{\text {aaa bbb ccc }}$ & $73.20+0.21^{\text {aaa bbb ccc }}$ & $96.60+0.24^{\text {aaa bbb ccc }}$ & $130.60+0.06^{\text {aaa bbb ccc }}$ \\
\hline $200 \mathrm{mg} / \mathrm{kg}$ & $63.80+0.20$ aaa bbb cce ddd & $75.40+0.14^{\text {aaa bbb ccc ddd }}$ & $110.00+0.12^{\text {aaa bbb ccc ddd }}$ & $122.00+0.24^{\text {aaa bbb ccc ddd }}$ & $125.20+0.09^{\text {aaa bbb ccc ddd }}$ \\
\hline $300 \mathrm{mg} / \mathrm{kg}$ & $55.00+0.14^{\text {aaa bbb ccc ddd eee }}$ & $76.20+0.14^{\text {aaa bbb ccc ddd eee }}$ & $76.20 \pm 0.14^{\text {aaa bbb ddd eee }}$ & $79.60+0.14^{\text {aaa bbb ddd eee }}$ & $130.40+0.09^{\text {aaa bbb ddd eee }}$ \\
\hline
\end{tabular}

$76.20+0.14^{\text {aaa bbb ddd eee }}$

$99.60+0.14^{\text {aaa bbb ddd ee }}$

${ }^{b}=\mathrm{CO}$ as reference ${ }^{\mathrm{b}}=$ significant at $\mathrm{p}<0.05{ }^{\mathrm{bb}}=$ significant at $\mathrm{p}<0.01$; ${ }^{\mathrm{bbb}}=$ significant at $\mathrm{p}<0.001$ )

${ }^{c}=50 \mathrm{mg} / \mathrm{kg}$ as reference $\left({ }^{\mathrm{c}}=\right.$ significant at $\mathrm{p}<0.05 ;{ }^{\mathrm{cc}}=$ significant at $\mathrm{p}<0.01 ;{ }^{\mathrm{ccc}}=$ significant at $\left.\mathrm{p}<0.001\right)$

$\mathrm{d}=100 \mathrm{mg} / \mathrm{kg}$ as reference $\left({ }^{\mathrm{d}}=\right.$ significant at $\mathrm{p}<0.05{ }^{\mathrm{dd}}=$ significant at $\mathrm{p}<0.01$; ${ }^{\mathrm{ddd}}=$ significant at $\left.\mathrm{p}<0.001\right)$

${ }^{\mathrm{e}}=200 \mathrm{mg} / \mathrm{kg}$ as reference $\left({ }^{\mathrm{e}}=\right.$ significant at $\mathrm{p}<0.05 ;{ }^{\mathrm{ee}}=$ significant at $\mathrm{p}<0.01 ;{ }^{\mathrm{eee}}=$ significant at $\left.\mathrm{p}<0.001\right)$

$(\mathrm{n}=5)$.

Table 3: Intestinal transit data.

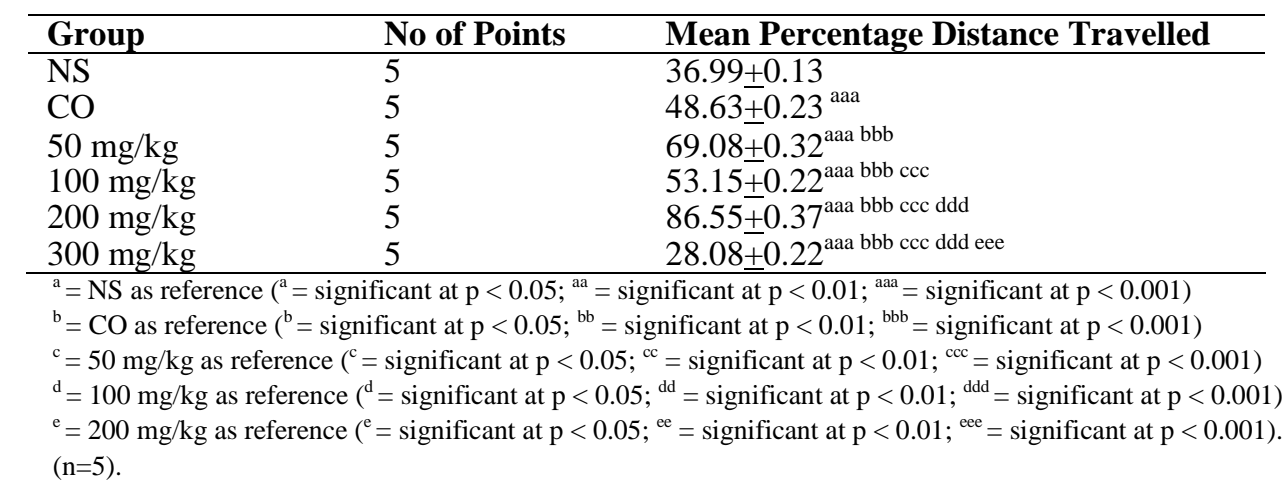


R. O. AKOMOLAFE et al. / Int. J. Biol. Chem. Sci. 5(6): 2371-2381, 2011

Table 4: Effects of AAV on the number of fecal pellets following loperamide-induced constipation.

\begin{tabular}{llllll}
\hline Dose & 2nd hr & 4th hr & 6th hr & 8th hr & 24th hr \\
\cline { 2 - 5 } & No. & No. & No. & No. & No. \\
\hline Nor mal. S. & $2.40 \pm 0.55$ & $2.40 \pm 0.55$ & $2.80 \pm 0.45$ & $3.00 \pm 0.00$ & $6.00 \pm 1.23$ \\
Castor Oil & $0.40 \pm 0.55^{\text {aaa }}$ & $0.40 \pm 0.55^{\text {aaa }}$ & $0.40 \pm 0.55^{\text {aaa }}$ & $0.80 \pm 0.45^{\text {aaa }}$ & $4.80 \pm 0.45$ \\
$200 \mathrm{mg} / \mathrm{kg}$ & $2.00 \pm 0.71^{\text {bb }}$ & $2.60 \pm 0.55^{\text {bbb }}$ & $3.00 \pm 0.00^{\text {bbb }}$ & $3.00 \pm 0.00^{\text {bb }}$ & $8.00 \pm 1.00^{\text {abbb }}$ \\
$300 \mathrm{mg} / \mathrm{kg}$ & $1.00 \pm 0.71^{\text {a }}$ & $1.00 \pm 0.71^{\text {aa ee }}$ & $1.00 \pm 0.71^{\text {aaa eee }}$ & $1.00 \pm 0.71^{\text {aaa eee }}$ & $8.20 \pm 1.10^{\text {abbb }}$ \\
\hline
\end{tabular}

${ }^{a}=$ NS as reference ${ }^{a}=$ significant at $p<0.05 ;{ }^{\text {aa }}=$ significant at $p<0.01 ;{ }^{\text {aaa }}=$ significant at $\left.\mathrm{p}<0.001\right)$

$\mathrm{b}=\mathrm{CO}$ as reference $\left({ }^{\mathrm{b}}=\right.$ significant at $\mathrm{p}<0.05 ;{ }^{\mathrm{bb}}=$ significant at $\mathrm{p}<0.01$; ${ }^{\mathrm{bbb}}=$ significant at $\left.\mathrm{p}<0.001\right)$

${ }^{\mathrm{e}}=200 \mathrm{mg} / \mathrm{kg}$ as reference $\left({ }^{\mathrm{e}}=\right.$ significant at $\mathrm{p}<0.05 ;{ }^{\text {ee }}=$ significant at $\mathrm{p}<0.01 ;{ }^{\text {eee }}=$ significant at $\left.\mathrm{p}<0.001\right)$.

$(\mathrm{n}=5)$

Table 5: Effects of AAV on the weight of fecal pellets following loperamide-induced constipation.

\begin{tabular}{|c|c|c|c|c|c|}
\hline \multirow[t]{2}{*}{ Dose } & 2nd hr & 4th hr & 6th hr & 8th hr & 24th hr \\
\hline & Wt (mg) & Wt (mg) & Wt (mg) & Wt (mg) & Wt (mg) \\
\hline Nor mal. S. & $33.18 \pm 0.13$ & $76.68 \pm 0.19$ & $37.42 \pm 0.22$ & $40.10 \pm 0.16$ & $85.86 \pm 0.30$ \\
\hline Castor Oil & $7.16 \pm 0.17^{\text {aaa }}$ & $7.16 \pm 0 .{ }^{\text {1aaa } 7}$ & $7.16 \pm 0.17^{\text {aaa }}$ & $15.98 \pm 0.15^{\text {aаa }}$ & $83.56 \pm 0.30^{\text {aaa }}$ \\
\hline $200 \mathrm{mg} / \mathrm{kg}$ & $15.98 \pm 0.13^{\text {aaa bbb }}$ & $18.58 \pm 0.25^{\text {aaa bbb }}$ & $22.58 \pm 0.22^{\text {aaa bbb }}$ & $22.58 \pm 0.22^{\text {aaa bbb }}$ & $70.46 \pm 0.31^{\text {aaa bbb }}$ \\
\hline $300 \mathrm{mg} / \mathrm{kg}$ & $9.56 \pm 0.15^{\text {aaa bbb eee }}$ & $9.56 \pm 0.15^{\text {aaa bbb eee }}$ & $9.56 \pm 0.15^{\text {aaa bbb eee }}$ & $9.56 \pm 0.15^{\text {aaa bbb eee }}$ & $107.20 \pm 0.37^{\text {aaa bbb eee }}$ \\
\hline
\end{tabular}

${ }^{\mathrm{a}}=\mathrm{NS}$ as reference ${ }^{\mathrm{a}}=$ significant at $\mathrm{p}<0.05 ;{ }^{\mathrm{aa}}=$ significant at $\mathrm{p}<0.01$; ${ }^{\text {aaa }}=$ significant at $\left.\mathrm{p}<0.001\right)$

$\mathrm{b}=\mathrm{CO}$ as reference $\left({ }^{\mathrm{b}}=\right.$ significant at $\mathrm{p}<0.05 ;{ }^{\mathrm{bb}}=$ significant at $\mathrm{p}<0.01$; ${ }^{\mathrm{bbb}}=$ significant at $\left.\mathrm{p}<0.001\right)$

${ }^{\mathrm{e}}=200 \mathrm{mg} / \mathrm{kg}$ as reference $\left({ }^{\mathrm{e}}=\right.$ significant at $\mathrm{p}<0.05 ;{ }^{\text {ee }}=$ significant at $\mathrm{p}<0.01 ;{ }^{\text {eee }}=$ significant at $\left.\mathrm{p}<0.001\right)$.

$(\mathrm{n}=5)$. 
R. O. AKOMOLAFE et al. / Int. J. Biol. Chem. Sci. 5(6): 2371-2381, 2011

Table 6: Effects of some receptor blockers on the number of fecal pellets following administration of AAV.

\begin{tabular}{llllll}
\hline Dose & 2nd hr & 4th $\mathbf{~ h r}$ & 6th $\mathbf{~ h r}$ & 8th $\mathbf{~ h r}$ & 24th hr \\
\cline { 2 - 5 } & No. & No. & No. & No. & No. \\
\hline Nor mal. S. & $7.40 \pm 0.55$ & $7.60 \pm 0.55$ & $7.60 \pm 0.55$ & $7.60 \pm 0.55$ & $8.60 \pm 0.55$ \\
ATR & $5.80 \pm 1.10^{\text {a }}$ & $7.00 \pm 0.71$ & $7.60 \pm 0.55$ & $7.60 \pm 0.55$ & $7.60 \pm 0.55$ \\
CHL & $5.00 \pm 1.00^{\text {aaa }}$ & $5.40 \pm 0.55^{\text {aaa }}$ & $6.00 \pm 0.00^{\text {aaa }}$ & $7.00 \pm 0.00$ & $9.40 \pm 0.55$ \\
PRO & $5.40 \pm 0.85^{\text {aa }}$ & $5.40 \pm 0.55^{\text {aaa }}$ & $5.60 \pm 0.55^{\text {aaa }}$ & $5.60 \pm 0.55^{\text {aaa }}$ & $7.40 \pm 0.55$ \\
NIF & $3.40 \pm 0.55^{\text {aaa }}$ & $3.40 \pm 0.55^{\text {aaa }}$ & $4.40 \pm 0.55^{\text {aaa }}$ & $5.40 \pm 0.55^{\text {aaa }}$ & $5.40 \pm 0.55^{\text {aaa }}$ \\
HEX & $6.60 \pm 0.55$ & $7.00 \pm 0.00$ & $8.00 \pm 0.71$ & $8.00 \pm 0.71$ & $10.00 \pm 1.00^{\text {a }}$ \\
\hline
\end{tabular}

${ }^{\mathrm{a}}=\mathrm{NS}$ as reference $\left({ }^{\mathrm{a}}=\right.$ significant at $\mathrm{p}<0.05 ;{ }^{\text {aa }}=$ significant at $\mathrm{p}<0.01 ;{ }^{\text {aaa }}=$ significant at $\left.\mathrm{p}<0.001\right)$

$(n=5)$.

Table 7: Effects of some receptor blockers on the weight of fecal pellets following administration of AAV.

\begin{tabular}{|c|c|c|c|c|c|}
\hline \multirow[t]{2}{*}{ Dose } & 2nd hr & 4th hr & 6th hr & 8th hr & 24th hr \\
\hline & Wt (mg) & Wt (mg) & Wt (mg) & Wt (mg) & Wt (mg) \\
\hline Nor mal. S. & $78.14 \pm 0.24$ & $83.20 \pm 0.26$ & $83.20 \pm 0.26$ & $83.20 \pm 0.26$ & $98.06 \pm 0.31$ \\
\hline ATR & $58.16+0.23^{\text {aаa }}$ & $93.78 \pm 0.20^{\text {aаa }}$ & $104.74 \pm 0.48$ aаa & $104.74 \underline{ \pm}+0.48$ aаa & $104.74 \underline{4}+0.48$ aаa \\
\hline CHL & $48.36 \pm 0.30^{\text {aaa }}$ & $53.44 \pm 0.31$ aаa & $59.80 \pm 0.51^{\text {aaa }}$ & $72.28 \pm 0.40^{\text {aаa }}$ & $95.04 \pm 0.21^{\text {aаa }}$ \\
\hline PRO & $68.40 \pm 0.53^{\text {аaа }}$ & $68.40 \pm 0.53^{\text {ааа }}$ & $72.46 \pm 0.40$ aаa & $72.46 \pm 0.40$ aаa & $94.62 \pm 0.45^{\text {аaа }}$ \\
\hline NIF & $35.58+0.36^{\text {aаa }}$ & $35.58+0.36^{\text {aaa }}$ & $44.90+0.19^{\text {aаa }}$ & $56.06+0.24^{\text {aaa }}$ & $56.06+0.24^{\text {aаa }}$ \\
\hline HEX & $92.24 \pm 0.17^{\text {aaa }}$ & $98.62+0.51^{\text {aaa }}$ & $112.40 \pm 0.51^{\text {aаa }}$ & $125.60 \pm 0.41^{\text {aаa }}$ & $140.00 \pm 0.51^{\text {aaa }}$ \\
\hline
\end{tabular}




\section{DISCUSSION}

The effects of the doses of AAV used in this study $(50-300 \mathrm{mg} / \mathrm{kg}$ ) on the number of fecal pellets produced by the mice do not appear to be dose dependent. However, a dose of $200 \mathrm{mg} / \mathrm{kg}$ of the extract consistently produced significantly higher numbers of fecal pellets than NS throughout the study. It also produced higher number of fecal pellets than $\mathrm{CO}$ in most periods of the experiment (Table 1). Considering the weight of the pellets, all the doses of AAV produced significantly higher fecal pellet weights than NS throughout the study (Table 2). Again, its effect was not dose dependent. This is the first report of the effects of AAV on the output of feces in mice. The study showed that AAV facilitates defecation in mice by causing bigger pellets to be produced. The number and weight of fecal pellets produced by mice that received $\mathrm{CO}$ got to their peaks at the $4^{\text {th }}$ hour of the observation period and remained unchanged throughout the rest of the period, while all the doses of AAV produced gradual increases in fecal pellet weights throughout the period of study. Some of the pellets produced by mice that received $\mathrm{CO}$ were actually wet. No wet feces was produced by the doses of AAV used in this study, A dose of $200 \mathrm{mg} / \mathrm{kg}$ of AAV produced significantly higher pellet weight than $\mathrm{CO}$ between 6 th and 24 th hour of the study. It was only at the $24^{\text {th }}$ hour of the study that 100 and $300 \mathrm{mg} / \mathrm{kg}$ of AAV produced a significantly higher pellet weight than $\mathrm{CO}$. This could be as a result of the recovery of the mice from the influence of the extract. At all other periods of the observation, the weights of the fecal pellets produced by mice that received the different doses of AAV were significantly lower than that of mice that got CO. Castor oil is known to cause water and electrolyte permeability changes in the intestinal mucosal membranes, resulting in fluid and watery luminal contents that flow rapidly through the small and large intestines (Gaginella et al., 1975; Mbagwu and Adeyemi, 2008).

Since no wet feces were produced by the mice that were treated with AAV, it was concluded that the mechanisms by which $\mathrm{AAV}$ and $\mathrm{CO}$ caused increased fecal pellet output were not the same. That was the reason why we decided to investigate the mechanism of action of the extract using some receptor blockers. The non dose dependent effects of the extract on the parameters studied could be attributed to its toxicity in mice, as evident by tremor in some of the mice that received 300 $\mathrm{mg} / \mathrm{kg}$, the highest dose of the extract used.

Doses of AAV caused more significant but not dose-dependent increases in intestinal transit than NS and CO up till $200 \mathrm{mg} / \mathrm{kg}$ (Table 3). At $300 \mathrm{mg} / \mathrm{kg}$, intestinal transit was significantly lower than both in NS and CO. This study indicates that AAV increases fecal pellet output of mice by increasing the rate of propulsive movement of their intestine. Chemical analysis of AAV indicates the presence of saponins and steroids. These substances may also be responsible for the increased propulsive movement caused by the extract.

Throughout the observation period, mice that were pre-treated with loperamide produced significantly higher number of fecal pellets when treated with $200 \mathrm{mg} / \mathrm{kg}$ of AAV than those that were treated with $\mathrm{CO}$, while those that were treated with $300 \mathrm{mg} / \mathrm{kg}$ of AAV produced significantly fewer fecal pellets than those treated with CO (Table 4). However, Table 5 shows that within the first eight hours of the study, both doses of AAV produced significantly greater fecal pellet weights than CO. The doses of AAV used in this study were able to reverse the loperamideinduced constipation in mice better than CO. Loperamide inhibits gastrointestinal motility (propulsion), reduces intestinal fluid secretion and accumulation, and delays gastric emptying, while $\mathrm{CO}$ induces diarrhea and ameliorate constipation by causing water and 
electrolyte permeability changes in the intestinal mucosal membranes, resulting in fluid and watery luminal contents that flow rapidly through the small and large intestines (Gaginella et al., 1975; Mbagwu and Adeyemi, 2008). Since the doses of AAV which were able to cause a significant reversal of the loperamide-induced constipation did not produce any wet feces even 24 hours after administration, the extract could serve as a better purgative than $\mathrm{CO}$ which induces defecation by increasing the secretory activity of the intestine. However, optimal absorption of nutrients requires adequate time of contact of digested food or chyme with the mucosa. Increased intestinal transit may reduce nutrient absorption by reducing the residence time of nutrients in the small intestine (Zhao et al., 1996). The increased intestinal transit induced by some doses of AAV could serve as a setback in exploring its use as a purgative.

The number of fecal pellets was significantly lower than the control (NS) in mice that received CHL (up to the $6^{\text {th }}$ hour), PRO (up to the $8^{\text {th }}$ hour) and NIF (throughout the observation period) (Table 6). The pellet weights of the mice that received the three blockers (CHL, PRO and NIF) were significantly lower than that of the control mice throughout the study. The pellet weights of the mice that received the remaining two blockers, that is, ATR and HEX, were significantly higher than that of the control mice, except at the $2^{\text {nd }}$ hour when it was significantly lower in mice that received ATR (Table 7). This study indicated that $\mathrm{H}_{1}$ receptors and $\mathrm{L}$ type $\mathrm{Ca}^{2+}$ channels, are mainly involved in the increased fecal pellet output that was observed with the administration of AAV. Cholinergic receptors appear to play no significant role in the increased motility induced by AAV, as evidenced by the inability of ATR and HEX to block the effects of the extract. It is therefore concluded that AAV increases the peristaltic movement of the intestine of mice by stimulating $\mathrm{H}_{1}$ receptors and opening up of $\mathrm{L}$ type calcium channels along the lining of their intestine. The influence of AAV on calcium channels calls for caution in the consumption of Anaphe venata larvae and suggestive of its involvement in the seasonal ataxia often associated with its consumption in some parts of Nigeria.

\section{REFERENCES}

Adamolekun B. 1992. A seasonal ataxic syndrome in South Western Nigeria: an etiological hypothesis of acute thiamine deficiency. Ethn. Dis., 2: 185-186.

Adamolekun B, Faleyimu BL, Selo-Ojeme D. 1993. Seasonal ataxic syndrome in a pregnant Nigerian woman. Int. J. Gynecol. Obstet., 4: 187-186.

Ashiru MO. 1988. The food value of Anaphe venata larvae Buttler (Lepidoptera: Notodontidae). Ecology of Food and Nutrition, 22: 313-320.

De Follart GR. 1989. The Human used of Insects as food and feed. Bulletin Entomological Society in America, 35: 22-35.

Ene TC. 1963. Insects and Man in West Africa. Ibadan University Press: Ibadan.

Gaginella TS, Stewart JJ, Olsen WA, Bass P. 1975. Action of ricinoleic acid and structurally related fatty acid on gastrointestinal tract. II. Effect on water and electrolyte absorption in vitro. J. Pharmacol. Exp. Ther., 195: 355-361.

Gamaliel KS, Akah PA. 1996. Analysis of the gastrointestinal relaxing effects of the stem bark extract of Gongronema latifolium. Phytomed., 2: 293-296.

Iwalewa EO, Onayade OA, Oyedapo OO, Daniyan OM. 2005. Sub-acute toxicity and biochemical effects of extracts of Anaphe venata larvae in mice. Afr. J. Biomed. Res., 8: 89-93.

Mbagwu HOC, Adeyemi OO. 2008. Antidiarrhoeal activity of the aqueous extract of Mezoneuron benthamianum Baill 
(Caesalpinaceae). J. Ethnopharmacol., 116: 16-20.

Ojewole JAO, Awe EO, Witness DHC. 2008. Antidiarrhoeal activity of Psidium guajava Linn (Myrtaceae) leaf aqueous extract in roedents. J. Smooth Muscle Res., 44(6): 195-207.

Onayade OA, Iwalewa EO, Adamolekun B, Omobuwajo OR. 2004. Behavioural effects and toxicity potentials of nonpolar and polar extracts of Anaphe venata larvae in mice. Ham. Medic., XLVII: 153-156.
Umoh IB, Ayalonu EO, Bassir O. 1980. Evaluation of the nutritive value of some lesser known protein sources in Nigerian peasants diets. Ecology of Food and Nutrition, 9: 81-86.

Zhao XT, Miller RH, McCamish MA, Wang L, Lin HC. 1996. Protein absorption depends on load-dependent inhibition of intestinal transit in dogs. American Journal of Clinical Nutrition, 64: 319323. 